\section{Estudo \\ Ecidebate}

em Testão

Dlanejamento
Revista Estudo \& Debate, Lajeado, v. 26, n. 2, 2019. ISSN 1983-036X

DOI: http://dx.doi.org/10.22410/issn.1983-036X.v26i2a2019.1668

\title{
UMA APLICAÇÁO DA ANÁLISE FUNDAMENTALISTA NO SETOR DE TRANSPORTES UTILIZANDO O MÉTODO DAS COMPONENTES PRINCIPAIS
}

\author{
Thiago de Souza Barros ${ }^{1}$, Carlos Eduardo da Gama Torres ${ }^{2}$
}

\begin{abstract}
Resumo: A demanda por transportes decorre da necessidade de se satisfazer as lacunas espaciais de atividades diversas e, no caso brasileiro, mediante a oferta inadequada de infraestrutura de transportes, tanto em termos de qualidade, quanto quantidade e participação modal, torna-se ainda mais importante uma melhor compreensão não só dos aspectos "físicos" da infraestrutura como os aspectos inerentes à regulaçáo e gestão do sistema. Neste contexto, foram calculados os principais índices contábeis e financeiros (liquidez, estrutura, rentabilidade e mercado) para medir o desempenho de 12 empresas do setor de transporte e logística do Brasil, listadas na BM\&FBovespa, no período compreendido entre 2008-2017. Com o intuito de simplificar a compreensão deste tipo de análise fundamentalista, esta pesquisa se utiliza da técnica estatística de análise de componentes principais para obter maior objetividade analítica. Os resultados de toda a série captaram que a LLX já apresentava resultados aquém da média de mercado, o que foi confirmado, posteriormente, pelos prejuízos acumulados nos últimos anos e que culminou, tratando-se da economia real, de mudança no nome da companhia e queda acentuada no valor de suas açóes. Por outro lado, LogIn e Trevisa tiveram os melhores resultados contábeis e financeiros. Por fim, é possível inferir também que a ACP contribuiu da forma esperada para o tratamento de dados, o que trouxe maior eficiência e simplificação no processo de análise.
\end{abstract}

Palavras-chave: Análise Fundamentalista, Análise de Componentes Principais, Setor de Transportes.

\section{AN APPLICATION OF FUNDAMENTAL ANALYSIS IN TRANSPORTATION SECTOR USING THE METHOD OF PRINCIPAL COMPONENTS}

\begin{abstract}
The demand for transport is due to the need to satisfy the space gaps of diverse activities and, in the brazilian case, through the inadequate supply of transport infrastructure, both in terms of quality, quantity and modal participation, it becomes even more important to better understanding not only of the "physical" aspects of the infrastructure but also the aspects inherent in the regulation and management of the system. In this context, the main accounting and financial ratios (liquidity, structure, profitability and market) were
\end{abstract}

1 Doutorando em Administração FGV-SP e professor do Departamento de Economia da Universidade Federal de Ouro Preto;

2 Doutor em Economia - CEDEPLAR - UFMG e professor do Departamento de Economia da Universidade Federal de Ouro Preto. 
calculated to measure the performance of 12 companies in the transport and logistics sector in Brazil, listed on the BM\&FBovespa, in the period 2008-2017. In order to simplify the understanding of this type of fundamentalist analysis, this research uses the statistical technique of analysis of principal components to obtain greater analytical objectivity. The results of the whole series showed that LLX already had results below the market average, which was later confirmed by the accumulated losses in recent years and which, in the case of the real economy, resulted in a change in the company name and decline in the value of its shares. On the other hand, LogIn and Trevisa had the best accounting and financial results. Finally, it is possible to infer also that the ACP contributed as expected to the data processing, which brought greater efficiency and simplification in the analysis process.

Keywords: Fundamental Analysis, Principal Component Analysis, Transportation Sector.

\section{Introduçáo}

As firmas compilam seus dados em suas demonstraçôes financeiras com o intuito de proporcionar uma melhor avaliação de sua situação econômica, patrimonial e financeira (IUDÍCIBUS et al, 2010; BASSO, FILIPIN e ENDERLI, 2015). Em consonância com este preceito, o normativo contabilístico tem como propósito gerar informações confiáveis de modo que se possa avaliar a natureza, os riscos, os efeitos financeiros das decisóes tomadas por uma empresa ao longo de um exercício e compreender o quanto isto pode impactar na rentabilidade da mesma (PADOVEZE e BENEDICTO, 2014; SOUSA e SANTOS, 2017). Portanto, informações contábeis de qualidade possuem também a função de "proteger" os acionistas minoritários de qualquer companhia.

Superados os aspectos de preparação e divulgação dos demonstrativos contábeis chega-se a uma etapa crucial do processo de tomada de decisóes de investimento: a análise acurada de suas demonstraçōes (MARION, 2010; OLIVEIRA; CUNHA, 2015). As técnicas de análise surgiram no segmento bancário e foram aperfeiçoadas ao longo do tempo (MATARAZZO, 2010; NIEDERAUER, VENDRUSCOLO e SALLABERRY, 2018), com o surgimento de uma gama de indicadores que servem de instrumento para efeito da justa avaliaçáo e comparação dos resultados da ação administrativa de empresas distintas (ASSAF NETO, 2012; RIBEIRO, 2012; PENMAN, 2013).

Desde então, a Análise Fundamentalista tem papel primordial na avaliação econômico-financeiro das firmas, pois através do estudo dos diversos índices que compóem essa análise é possível verificar a conjuntura financeira da empresa para um possível investimento (PENMAN, 2013; PADOVEZE e BENEDICTO, 2014; TAGLIARI; SANTOS e RODRIGUES, 2017). Entretanto, o estudo de todos os índices que compóem a análise fundamentalista requer "tempo" e informaçóes diversas, fazendo com que essa análise assuma uma diversidade de números para subsidiar o cálculo de inúmeros quocientes.

A fim de mitigar os aspectos críticos delineados no parágrafo anterior, este artigo propóe uma análise que tem como objetivo simplificar a compreensão da análise fundamentalista, tornando-a mais objetiva. Para tanto, propóe-se a construção de índices de desempenho gerados por meio da técnica estatística da Análise de Componentes Principais (ACP). Essa técnica visa à redução de vetores que possuem muitas dimensóes, e permite transformar, a partir de combinaçôes lineares, as variáveis originais em variáveis não correlacionadas (MINGOTTI, 2005; EVERITTI, 2005; MOROZINI, OLINQUEVITCH e HEIN, 2006). Assim, o emprego da ACP no estudo da situação econômico-financeira de uma 
empresa simplifica a compreensão dos diversos índices levantados a partir da Análise Fundamentalista.

Destarte, o objetivo geral deste estudo é realizar uma pesquisa quantitativa para analisar o desempenho das empresas do setor de transporte e logística do Brasil que possuem ações na bolsa de valores. Para este efeito, buscou-se conciliar duas tradições teóricas distintas a análise dos principais índices fundamentalistas (indicadores de liquidez, estrutura, rentabilidade e mercado) e a análise estatística (por meio da Análise de Componentes Pincipais). A amostra foi selecionada por intencionalidade e acessibilidade, não respeitando qualquer critério de aleatoriedade.

Todavia, a escolha pelo setor de transporte e logística justifica-se pela relevância econômica deste setor e, considerando-se particularmente o caso brasileiro, dados os diversos gargalos infraestruturais e a dificuldade em se sanar o problema. Considerando-se ainda que uma vez que o Brasil é um país com predomínio do modal rodoviário em sua matriz de transportes e que o processo de concessão da malha sob jurisdição do Estado é relativamente recente, é importante compreender o desempenho das empresas concessionárias para que se possa balizar as tarifas impostas à sociedade de modo que os serviços ofertados garantam por um lado segurança e comodidade aos usuários a preços justos e, por outro lado mantenha o equilíbrio econômico financeiro das concessionárias (BROCHADO e VASSALO, 2014; THE ECONOMIST, 2015; BLANK et al, 2015; NETO, MOREIRA e MOTTA, 2018). Ademais, a situação financeira de uma gama de empresas deste setor está vulnerável e os custos são consideráveis, nuances que justificam ainda mais este trabalho. A recente greve de caminhoneiros ocorrida no Brasil (Valor, 2018), que parou o país e arrefeceu o crescimento econômico (Financial Times, 2018) é outro fator que reforça a importância de se entender este conjunto de empresas.

Conjuntamente com a revisão bibliográfica realizada foram gerados alguns índices que pudessem sintetizar todo o conjunto de dados permitindo por outro lado que a análise financeira, econômica e contabilística do setor em questão se desse de maneira mais elucidativa.

\section{Fundamentaçáo Teórica}

\subsection{Análise Fundamentalista}

De acordo com Matarazzo (2010) a Análise de Balanços surgiu e desenvolveu-se dentro do sistema bancário, no final do século XIX, e, a partir de 1931, índices-padrão passaram a ser divulgados permitindo à comparação de diversos itens, o que viria a se tornar a tão útil análise e interpretação de demonstrativos contábeis.

Em traço geral, Periasamy (2010) advoga que o termo "análise" refere-se, estritamente, ao rearranjo dos dados apresentados nas demonstraçóes financeiras, enquanto o termo "interpretação" trata-se da explicação do significado e da importância desses dados analisados. Dessa feita, as análises e interpretaçôes estão intimamente ligadas e interrelacionadas, demonstrando uma característica de complementariedade entre si. 
Neste vértice de análise, White, Sondhi e Fried (2002) preconizam que a principal utilidade das demonstraçóes financeiras é ajudar investidores e credores a tomarem as melhores decisóes econômicas e, por isso, em consonância com Metcalf e Tigard apud Periasamy (2010), Padoveze e Benedicto (2014), Sousa e Santos (2017), a análise e interpretação desses demonstrativos contábeis é, basicamente, um processo de avaliar a relação entre os componentes que compóem um demonstrativo financeiro para obter-se uma melhor compreensão da posição e do desempenho de uma empresa em determinado período.

Suresh (2013) reforça que os investidores dependem fortemente desses fatores fundamentalistas em suas decisóes de investimentos, pois podem conhecer os fundamentos de natureza econômica e financeira de determinada empresa, setor ou economia (OLIVEIRA e CUNHA, 2015; TAGLIARI; SANTOS e RODRIGUES, 2017; NIEDERAUER, VENDRUSCOLO e SALLABERRY, 2018).

Em face dessa relevância e necessidade, com o passar dos anos novas teorias vêm a incrementar todo o arcabouço contabilístico, financeiro e econômico, com o surgimento de novas fórmulas e indicadores para entendimento dos dados divulgados nas demonstraçóes financeiras das firmas (CHESNICK, 2000; WHITE, SONDHI \& FRIED, 2002; GITMAN, 2006; LESÁVOKÁ, 2007; HORNE e WACHOWICZ, 2009; PERIASAMY, 2010; SALEEM e REHMAN, 2011; PENMAN, 2013; PADOVEZE e BENEDICTO, 2014).

Tecidas tais consideraçóes e partindo da premissa de que os índices de análise fundamentalista já foram amplamente explorados em outros trabalhos, além de ser uma matéria de vasto domínio dos especialistas da área, esta seção do artigo focalizará somente a relação entre análise fundamentalista e a análise de componentes principais, observando as principais pesquisas desenvolvidas neste sentido.

Por este prisma de observaçáo, insta ressaltar que autores como Morozini, Olinquevitch e Hein (2006) examinaram a situação econômico-financeira de sociedades anônimas em processo de concordata na cidade de Curitiba/PR, fazendo uso da ACP aos indicadores contábeis das entidades e validando a importância desta metodologia estatística para este propósito.

Contudo, os autores utilizaram uma série temporal restrita (2001 a 2003) e visaram, após o cálculo dos componentes principais através dos valores obtidos na matriz de covariância, evidenciar a existência de tendência nestas situaçóes de concordata. Dessa forma, eles utilizaram a ACP simplesmente para demonstrar quais variáveis eram mais relevantes neste cenário de insolvência, descartando àquelas que apresentavam baixa representatividade no ato de explicar a variabilidade total dos dados.

Santos e Greuel (2010) caminharam na mesma direção do artigo ora em apreço e fizeram uso da ACP para analisar a gestão financeira e econômica dos clubes de futebol brasileiros. Também utilizaram uma série temporal curta (2007-2009) e observaram apenas os dados obtidos pela ACP em relaçáo ao posicionamento de cada agremiação em relaçáo a colocação divulgada pela Confederação Brasileira de Futebol (CBF). 
Não obstante, Gollo e Silva (2014) utilizaram a ACP para verificar a eficiência global no desempenho econômico-financeiro de cooperativas de crédito brasileiras, partindo da metodologia denominada pelo acrônimo PEARLS, mas com um propósito de pesquisa completamente diferente desta em voga.

Transcendendo os estudos até então realizados, este artigo utilizou uma série temporal mais extensa (2008-2017) e, após calcular os indicadores contábeis e financeiros utilizou-se a técnica de ACP em quatro anos amostrais (2008, 2012, 2015 e 2017) com o intuito de compreender a evolução das empresas ao longo do tempo por meio de uma síntese de seus indicadores contábeis. Além de buscar uma compreensão do desempenho das empresas do setor de transportes e logística a análise por meio da ACP visou tornar mais objetiva os resultados das demonstraçóes contábeis, o que até então não tinha sido elaborado por nenhuma pesquisa anterior. Vale salientar que os resultados alcançados a partir da ACP estão de acordo com as sinalizaçóes do mercado de capitais no que tange ao preço das açóes (com destaque para a LLX, que sofreu queda abrupta no preço de suas açóes e foi adquirida pelo grupo norte-americano EIG, passando a se chamar Prumo), permitindo comparar empresas distintas resumindo as informaçóes mais relevantes acerca das empresas para toda a série temporal analisada, o que caracteriza uma nova abordagem metodológica.

\subsection{Análise de Componentes Principais}

A técnica designada Análise de Componentes Principais (ACP), popularmente denominada PCA - devido ao termo em língua inglesa, foi introduzida por Pearson (1901), e aprimorada por Hotelling (1933), através de métodos computacionais. Em traço geral, a análise de componentes principais (ACP) é um método estatístico que tem por finalidade transformar as variáveis originais observadas, reduzindo a dimensão do sistema e mantendo suas características essenciais.

Neste contexto, conforme aduz Mingotti (2005), o objetivo principal da ACP é explicar a estrutura de variância e covariância de um vetor aleatório por meio de combinações lineares das variáveis originais. Tais combinaçóes lineares são as chamadas componentes principais e possuem como propriedade fundamental o fato de serem não correlacionadas entre si.

Assim, as informaçóes contidas em p variáveis originais são substituídas pelas informaçóes contidas em $\mathrm{k}<\mathrm{p}$ componentes principais, de modo a reduzir a dimensão do vetor de covariadas simplificando o entendimento do problema. Neste contexto a utilizaçáo da ACP torna-se necessária quando existem muitas variáveis explicativas relativamente ao número de observaçóes e, quando tais variáveis são altamente correlacionadas (EVERITT, 2005).

A primeira componente principal é formada pela combinação linear

$$
\mathrm{y}_{1}=\mathrm{a}_{11} \mathrm{x}_{1}+\mathrm{a}_{12} \mathrm{x}_{2}+\ldots+\mathrm{a}_{\mathrm{iq}} \mathrm{x}_{\mathrm{q}}
$$

cuja variância amostral é a maior entre todas as combinaçóes lineares possíveis. Dado que a variância de $y_{1}$ poderia ser inflada artificialmente ao aumentarmos os coeficientes $a_{11}$, 
$\mathrm{a}_{12,}, \ldots, \mathrm{a}_{\mathrm{iq}}$ (ou seja, o vetor $\mathrm{a}_{1}$ ) deve-se colocar uma restriçãao para que o produto (entre os vetores) $a_{1}{ }^{\prime} a_{1}$ se iguale a 1 .

A segunda componente principal é formada pela combinação linear

$$
y_{2}=a_{21} x_{1}+a_{22} x_{2}+\ldots+a_{2 q} x_{q}
$$

cuja variância amostral é a segunda maior entre todas as combinações lineares possíveis considerando-se a seguinte restrição: $\mathrm{a}_{2}{ }^{\prime} \mathrm{a}_{1} 0$ (tal condição garante que $\mathrm{a}_{1}$ e $\mathrm{a}_{2}$ sejam não correlacionadas). As componentes principais são assim ordenadas de maneira decrescente em termos de explicação da variância total do sistema.

A solução deste problema de otimização condicionada, conforme Everitt (2005), aponta para que $a_{1}$ corresponda ao autovetor da matriz de covariância (ou correlação) amostral associada ao seu maior autovalor. Os outros componentes são derivados a partir do mesmo procedimento de modo que $\mathrm{a}_{\mathrm{j}}$ corresponda ao autovetor da matriz de covariância (ou correlação) amostral associada ao j-ésimo maior autovalor.

Para operacionalizarmos a ACP uma vez que a matriz de covariância populacional é desconhecida, inicialmente estimamos a partir da matriz original de dados X, analisada em $\mathrm{p}$ dimensóes, uma matriz de covariância (correlação) amostral $\left(\mathrm{S}_{\mathrm{pxp}}\right)$. Sejam $\lambda_{1}, \lambda_{2}, \ldots$. , $\lambda_{\mathrm{p}}^{\hat{0}}$ os autovalores da matriz $S_{\text {pxp }}$ e, sejam $\hat{a}_{1}, \hat{a}_{2}, \ldots . ., \hat{a}_{\mathrm{p}}$, os autovetores correspondentes, então a j-ésima componente principal amostral estimada é definida por: $\hat{y}_{j=} \hat{a}_{j 1} x_{1}+\hat{a}_{j 2} x_{2}+\ldots \ldots \hat{a}_{j p} x_{p}$, $\mathrm{j}=1,2, \ldots .$. . Segue abaixo algumas das principais propriedades das componentes principais amostrais (MINGOTTI, 2005):

a) A variância estimada de $\hat{y}_{j}$ é igual a $\lambda_{j}, j=1,2, \ldots . . p$;

b) As componentes principais são não correlacionadas;

c) Variància_Total_Estimada_de_X $=\frac{\lambda_{j}}{\sum_{i=1}^{p} \lambda_{j}}$

Neste diapasão, ao multiplicarmos as $k$ componentes principais estimadas por cada uma das $n$ observaçóes avaliadas nas suas $p$ dimensóes podemos calcular índices de desempenho para cada elemento amostral. Tais índices não significam nesse caso um desempenho melhor ou pior de cada uma das empresas em questão mas indica padróes discrepantes que podem explicitar as peculiaridades de cada firma em determinado ano (Rencher e Christensen, 2012).

Autores como Aitchison (1986) e Johnson (2007) estudaram à exaustão o modelo de análise de componentes principais. Huynh et.al (2011) investigaram a evolução de algumas empresas manufatureiras entrantes no mercado canadense por meio da análise de componentes principais funcionais. Nesse caso, modificou-se a análise de componentes principais tradicionais para permitir a inclusão de informaçóes qualitativas na forma de variáveis discretas, examinando variáveis de produção, tamanho e produtividade do trabalho, e uma variável financeira, alavancagem (relação dívida/ativo). 
Olawawe e Garwe (2011), por sua vez, utilizaram a ACP para compreender os obstáculos ao crescimento de pequenas e médias empresas na África do Sul. No Brasil, Lopes (2001) fez um trabalho substancial em que aplicou tal metodologia à confiabilidade de sistemas complexos, enquanto Teixeira (2013) fez vasta pesquisa econométrica, utilizando à ACP em séries temporais. Contudo, todos estes estudos estudaram a relevante temática em contextos distintos ao realizado nesta pesquisa, de modo que o uso de indicadores contábeis não se deu de maneira tão aprofundada.

\section{Metodologia}

Esta pesquisa de cariz quantitativo propóe a aplicação da técnica estatística de Análise das Componentes Principais aos demonstrativos financeiros de empresas que compóe a amostra. Ademais, é importante registrar que a amostra deste artigo foi definida de forma intencional por parte dos pesquisadores, seguindo uma escolha discricionária e não aleatória, e é constituída por todas as empresas do segmento de transporte e logística com açóes comercializadas na Bolsa de Valores de São Paulo, conforme Tabela 1.

Tabela 1: Empresas que compóem a amostra

\begin{tabular}{c}
\hline América Latina Logística (ALL) \\
\hline Arteris \\
\hline Companhia de Concessóes Rodoviárias (CCR) \\
\hline LLX (Prumo)* \\
\hline Log In \\
\hline Julio Simóes Logística (JSL) \\
\hline Santos Brasil Participações (SBP) \\
Triunfo \\
\hline Ecorodovias \\
Tegma \\
\hline Wilson Sons Logística \\
Trevisa
\end{tabular}

* A partir de 2013 a LLX tornou-se Prumo S.A.

Fonte: Elaborada pelos autores, 2019.

A série temporal estipulada compreende o período de 2008 a 2017, formando um período de 9 anos. Este período analisado justifica-se pela importância de uma análise com comparação temporal, pois possibilita acompanhar a evolução dos indicadores em determinado período de tempo, cuja ocorrência é normalmente de três a cinco anos conforme preconizado por Assaf Neto (2010). Como as empresas possuem capital aberto o acesso aos demonstrativos das mesmas não foi dificultado e os dados foram extraídos da base de dados da própria BM\&FBOVESPA.

Desse modo, após coletar os dados e compilar todas as informaçóes contidas nas demonstrações financeiras, foram calculados os índices econômico-financeiros das empresas 
e aplicadas estatísticas descritivas às diversas variáveis. Os indicadores analisados neste trabalho foram os listados a seguir, com as respectivas nomenclaturas (variáveis) utilizadas para as estimaçóes da ACP:

Tabela 2: Indicadores contábeis e financeiros, de análise fundamentalista, calculados.

\begin{tabular}{l|c}
\hline \multicolumn{1}{c}{ Identificação de Variáveis Contábeis e Financeiras } \\
\hline \multicolumn{1}{c}{ LIQUIDEZ } & LG \\
\hline Liquidez Geral & LC \\
\hline Liquidez Corrente & LS \\
\hline Liquidez Seca & LI \\
\hline Liquidez Imediata & Part.K3 \\
\hline Participação de Capitais de Terceiros & CE \\
\hline Composição de Endividamento & IPL \\
\hline Imobilização do Patrimônio Líquido & IRNC \\
\hline Imobilização dos Recursos Não Correntes & \\
\hline \multicolumn{1}{c|}{ RENTABILIDADE } & GA \\
\hline Giro do Ativo & ML \\
\hline Margem Líquida & RA \\
\hline Rentabilidade do Ativo & RPL \\
\hline Rentabilidade do Patrimônio Líquido & VPA \\
\hline \multicolumn{1}{c}{ MERCADO } & LPA \\
\hline Valor Patrimonial da Ação & \\
\hline Lucro por Ação & \\
\hline
\end{tabular}

Fonte: Elaborada pelos autores, 2019.

Em seguida, já de posse dos índices calculados para cada firma que compóe a amostra e para toda a série temporal pré-determinada, foi aplicada a análise de componentes principais desses índices, utilizando, para este efeito, o software STATA.

Primeiramente foram estimadas as correlaçôes existentes entre as quatorze variáveis sob análise, com o propósito de verificar se a adoção da metodologia ACP é de fato justificável. Procedeu-se ao cálculo dos autovalores e autovetores pertinentes à solução do problema e, em seguida, os dados amostrais foram multiplicados pelas cargas dos componentes principais a fim de gerar scores que representassem o desempenho de cada firma de acordo com o componente escolhido. A partir daí foram gerados gráficos com o intuito de possibilitar ao analista observar os pontos ocupados por cada empresa em um plano bidimensional, de acordo com as componentes em análise, de modo a identificar algum padrão discrepante.

Neste sentido, vale dizer que com a ACP o pesquisador pode primeiro identificar as dimensóes separadas da estrutura e "então determinar o grau em que cada variável é 
explicada por cada dimensão. Uma vez que essas dimensões e a explicação de cada variável estejam determinadas, os dois principais usos da análise de componentes principais-resumo e redução de dados - podem ser conseguidos" (COSTA, 2006). Assim, através deste método de estatística multivariada, foi possível alcançar resultados satisfatórios e cumprir com o objetivo principal deste estudo: condensar as principais informaçóes pertinentes - o que é um dificultador da análise fundamentalista quando esta é realizada em uma amostra de empresas e exercícios distintos, dadas os inúmeros índices que devem ser calculados, analisados e interpretados -, com menor perda possível da informação.

Em face da aplicação da ACP, pôde-se trabalhar com um número reduzido de variáveis que conseguiram explicar aproximadamente $90 \%$ da variância original do sistema em conformidade com o critério de Kaiser de se considerar somente autovalores próximos de 1 (Everitt, 2005).

\section{Apresentaçáo e Análise de Resultados}

Como bem relatado na etapa metodológica, após proceder à coleta dos dados, realizou-se à análise, discussão e apresentação dos resultados, visando garantir a sua precisão, evitar distorçôes de análise, discussão e interpretação, possibilitando, consequentemente, uma margem de segurança quanto às influências. (RICHARDSON, 1989).

Primeiramente, foram extraídos os dados dos demonstrativos financeiros das empresas que compóem a amostra e calculados os indicadores fundamentalistas para cada ano da série temporal determinada. Mesmo havendo evidências na literatura de que a adoção das normas internacionais de contabilidade (IFRS) ${ }^{3}$ é capaz de influenciar as demonstraçóes financeiras das firmas, apenas um número restrito de pesquisadores utilizam evidências empíricas para demonstrar esses efeitos oriundos da adesão a este normativo nos índices de desempenho das empresas, principalmente no Brasil.

Tendo em vista que em 2007, com a promulgação da Lei 11.638/2007, o Brasil aderiu, de forma ampla, ao normativo contabilístico internacional, somente a partir do exercício social de 2008 que, em sua grande maioria, as sociedades anônimas brasileiras adotaram tais práticas contábeis e esta pesquisa procurou abordar estes efeitos na análise realizada.

Em traço geral, vários autores discorreram a respeito do reflexo desse processo de convergência, harmonização e adoção de normas internacionais nos resultados de determinadas empresas, tais como Callao et al 2007; Costa e Lopes, 2008; Lantto e Sahlström, 2009; Lemes e Carvalho, 2009; e Klann et al (2009). Os estudos apontam que embora existam divergências que derivam das distinçóes latentes entre os dois padróes contabilísticos (o antigo BR Gaap e o atual IFRS), elas tende a desaparecer com a convergência normativa.

3 Insta ressaltar que IFRS refere-se ao International Financial Reporting Standard, conjunto de normas e pronunciamentos contábeis considerados padróes internacionalmente aceites de reporte financeiro, emitidos pelo IASB - International Accounting Standards Board. 
Outros pesquisadores, como é o caso de Barbosa Neto et al (2009), analisaram o impacto da alteração de normas contábeis realizada no Brasil e observaram que mesmo existindo algumas diferenças entre os indicadores calculados em IFRS e em BR GAAP, essas discrepâncias não apresentaram significância estatística.

Um dos aspectos críticos de se realizar qualquer procedimento estatístico utilizandose de séries temporais diz respeito à ocorrência das chamadas quebras estruturais, isto é, alteraçōes significativas da base de dados que interfira na análise em questão. Neste cenário, poder-se-ia argumentar que as alteraçôes no normativo contabilístico brasileiro, uma vez que em 2008 as sociedades anônimas adotavam o padrão de normas BR GAAP e que, somente a partir de 2009, passaram a divulgar as informaçóes contábeis em conformidade com as normas internacionais (IFRS), poderia se configurar como uma quebra estrutural, o que imputaria um viés à análise realizada. Para lidar com esta questão foram realizadas análises semelhantes para os anos de 2008, 2012, 2015 e 2017. Buscou-se assim traçar uma evolução do desempenho econômico das firmas ao longo do tempo.

Dadas estas consideraçóes podemos observar conforme a Tabela 3 que os indicadores contábeis selecionados são altamente correlacionados se considerarmos cada um dos grupos (liquidez, estrutura, rentabilidade e mercado). Nesse cenário, a utilização da técnica de ACP justifica-se não só pela alta correlação linear presente, mas também pelo fato de que analisamos 14 variáveis em uma amostra com 12 empresas. Dessa feita, de acordo com os dados referentes à 2015, considerando-se a dimensão de liquidez, apenas a variável LG é pouco correlacionada às demais variáveis do grupo. Considerando-se a dimensão estrutura, todas as quatro variáveis são bastante correlacionadas entre si, sendo a variável CE a menos correlacionada entre elas. Considerando-se a dimensão rentabilidade, temos que as quatro variáveis listadas apresentam alta correlação, mas em um grau menor do que nas dimensóes de liquidez e estrutura. As duas variáveis listadas na dimensão de mercado (VPA e LPA) apresentaram uma correlação moderada.

Tabela 3 - Matriz de Correlação Entre as 14 Variáveis Selecionadas em 2015 para as Empresas do Setor de Transportes

\begin{tabular}{c|r|r|r|r|r|r|r|r|r|r|l|l|l|l}
\hline Variáveis & LC & LS & LI & LG & Part.k3 & IPL & CE & IRNC & GA & ML & RA & RPL & VPA & LPA \\
\hline LC & 1,00 & & & & & & & & & & & & & \\
\hline LS & 1,00 & 1,00 & & & & & & & & & & & & \\
\hline LI & 0,90 & 0,91 & 1,00 & & & & & & & & & & & \\
\hline LG & 0,39 & 0,37 & 0,40 & 1,00 & & & & & & & & & & \\
\hline Part k 3 & $-0,45$ & $-0,45$ & $-0,46$ & $-0,51$ & 1,00 & & & & & & & & & \\
\hline IPL & $-0,50$ & $-0,50$ & $-0,49$ & $-0,50$ & 0,99 & 1,00 & & & & & & & & \\
\hline Comp. Endi & $-0,52$ & $-0,52$ & $-0,61$ & $-0,27$ & 0,70 & 0,71 & 1,00 & & & & & & & \\
\hline IRNC & $-0,59$ & $-0,59$ & $-0,55$ & $-0,40$ & 0,92 & 0,95 & 0,83 & 1,00 & & & & & & \\
\hline GA & 0,66 & 0,71 & 0,76 & 0,01 & $-0,27$ & $-0,29$ & $-0,39$ & $-0,31$ & 1,00 & & & & & \\
\hline ML & $-0,37$ & $-0,41$ & $-0,65$ & $-0,01$ & $-0,03$ & $-0,02$ & 0,31 & 0,00 & $-0,75$ & 1,00 & & & & \\
\hline RA & $-0,41$ & $-0,45$ & $-0,70$ & $-0,04$ & 0,11 & 0,12 & 0,43 & 0,15 & $-0,77$ & 0,99 & 1,00 & & & \\
\hline
\end{tabular}




\begin{tabular}{c|c|c|c|c|c|c|c|c|c|c|c|c|c|c}
\hline Variáveis & LC & LS & LI & LG & Part.k3 & IPL & CE & IRNC & GA & ML & RA & RPL & VPA & LPA \\
\hline RPL & $-0,37$ & $-0,40$ & $-0,65$ & $-0,01$ & $-0,01$ & 0,00 & 0,34 & 0,03 & $-0,75$ & 1,00 & 0,99 & 1,00 & & \\
\hline VPA & $-0,08$ & $-0,10$ & $-0,15$ & 0,26 & $-0,31$ & $-0,30$ & $-0,36$ & $-0,23$ & $-0,09$ & 0,20 & 0,15 & 0,17 & 1,00 & \\
\hline LPA & 0,31 & 0,32 & 0,42 & 0,32 & $-0,75$ & $-0,75$ & $-0,82$ & $-0,72$ & 0,41 & $-0,32$ & $-0,45$ & $-0,36$ & 0,64 & 1,00 \\
\hline
\end{tabular}

Fonte: Resultados da Pesquisa, 2019.

Uma análise "pura" dos indicadores fundamentalistas demonstra que em 2008, conforme a Tabela 4, que as empresas com melhores indicadores de liquidez eram Log In e Wilson Sons (tanto em liquidez geral, corrente, imediata ou seca), o que enfatiza que estas empresas possuíam alta capacidade de honrar seus compromissos, principalmente àqueles de curto prazo. Em contrapartida, as piores firmas foram Ecorodovias (em todos os índices de liquidez) e, em seguida, Trevisa (quanto à liquidez geral), Arteris (no que tange a liquidez corrente e seca) e CCR (no tocante a liquidez imediata). No espectro geral, a Log In foi a empresa com melhores indicadores de liquidez e a Ecorodovias a empresa com pior condição neste quesito.

Com relação aos indicadores de estrutura de capital, verifica-se que a ALL foi a firma com maior dependência de capital de terceiros, o que num cenário macroeconômico instável e de crise econômica internacional pode ser um péssimo indicador, tendo em conta a dificuldade de se obter crédito. Paralelamente a Log In e SBP apresentaram menor dependência de capital de terceiros. Contudo, desse endividamento total, é importante analisar apenas o que é de curto prazo, afinal essas são as dívidas que afetam diretamente o caixa das firmas.

Sob esse enfoque, a Ecorodovias e a Trevisa foram as empresas que apresentaram menor endividamento de curto prazo, ou seja, apenas 11\% das dívidas da Trevisa e $20 \%$ das dívidas da Ecorodovias eram de curto prazo. Se focalizarmos os índices de imobilização, seja somente do patrimônio líquido ou da totalidade dos recursos não correntes, observamos que a empresa com maior imobilização foi a CCR, seguida pela Ecorodovias (quando somados aos capitais próprios o passivo não circulante da companhia).

Tabela 4: Indicadores Fundamentalistas para 2008

\begin{tabular}{|c|c|c|c|c|c|c|c|c|c|c|c|c|c|c|}
\hline Empresas & LC & LS & LI & LG & Part.k3 & IPL & CE & IRNC & GA & ML & RA & RPL & VPA & LPA \\
\hline ALL & 1,44 & 1,40 & 1,15 & 0,44 & 3,71 & 2,99 & 0,25 & 0,79 & 0,23 & 0,07 & 0,02 & 0,07 & 0,87 & 0,06 \\
\hline Arteris & 0,43 & 0,42 & 0,27 & 0,12 & 2,14 & 2,70 & 0,25 & 1,03 & 0,34 & 0,15 & 0,05 & 0,14 & 11,81 & 1,53 \\
\hline CCR & 0,60 & 0,60 & 0,02 & 0,54 & 2,34 & 3,74 & 0,49 & 1,71 & 0,52 & 0,26 & 0,14 & 0,40 & 4,95 & 1,77 \\
\hline JSL & 0,50 & 0,48 & 0,11 & 0,38 & 2,00 & 1,79 & 0,53 & 0,92 & 0,97 & 0,04 & 0,04 & 0,09 & 3,39 & 0,29 \\
\hline LLX (Prumo) & 1,03 & 1,02 & 0,97 & 0,73 & 1,12 & 0,92 & 0,52 & 0,60 & 0,02 & $-3,22$ & $-0,08$ & $-0,17$ & 1,23 & 0,15 \\
\hline $\log$ In & 3,30 & 3,24 & 1,89 & 1,91 & 0,31 & 0,72 & 0,51 & 0,62 & 0,57 & 0,19 & 0,11 & 0,14 & 6,56 & 0,97 \\
\hline SBP & 1,00 & 0,98 & 0,67 & 0,78 & 0,36 & 1,08 & 0,62 & 0,95 & 0,00 & 0,00 & 0,03 & 0,04 & 1,72 & 0,10 \\
\hline Triunfo & 0,72 & 0,72 & 0,36 & 0,17 & 1,57 & 2,36 & 0,21 & 1,05 & 0,14 & $-0,30$ & $-0,04$ & $-0,12$ & 5,07 & $-0,66$ \\
\hline Ecorodovias & 0,23 & 0,23 & 0,08 & 0,12 & 2,26 & 3,00 & 0,48 & 1,38 & 0,50 & 0,16 & 0,08 & 0,23 & 1,25 & 0,27 \\
\hline Tegma & 1,34 & 1,33 & 0,40 & 0,99 & 0,82 & 1,00 & 0,65 & 0,78 & 1,78 & 0,05 & 0,10 & 0,16 & 4,90 & 0,80 \\
\hline
\end{tabular}




\begin{tabular}{|c|c|c|c|c|c|c|c|c|c|c|c|c|c|c|}
\hline Empresas & LC & LS & LI & LG & Part.k3 & IPL & CE & IRNC & GA & ML & RA & RPL & VPA & LPA \\
\hline Wilson & 3,24 & 3,13 & 2,18 & 1,04 & 0,84 & 0,97 & 0,30 & 0,61 & 0,95 & 0,09 & 0,09 & 0,16 & 10,91 & 1,54 \\
\hline Trevisa & 1,26 & 1,04 & 0,48 & 0,15 & 1,78 & 2,51 & 0,12 & 0,98 & 0,59 & $-0,08$ & $-0,05$ & $-0,12$ & 15,09 & $-1,96$ \\
\hline
\end{tabular}

Fonte: Resultados da Pesquisa, 2019.

Apesar de a doutrina contábil assumir que os indicadores de estrutura de capital devem ser analisados pela óptica de quanto menor melhor, deve-se fazer algumas ressalvas quanto a esta abordagem restrita, pois empresas do ramo de transportes e logística, podem necessitar de um alto índice de imobilização, até mesmo porque as principais fontes de receita das firmas advêm de seus ativos considerados permanentes. Todavia, no que concerne ao endividamento total e de curto prazo, a tônica de quanto menor melhor deve ser respeitada.

Com exceção do giro do ativo, todos os outros indicadores de rentabilidade demonstram maior solidez econômica, no ano de 2008, por parte da CCR, enquanto a LLX foi a firma com pior desempenho, demonstrando baixa capacidade de rentabilidade do patrimônio líquido e do ativo, gerando baixa margem líquida e prejuízos acumulados. $\mathrm{Na}$ esfera do giro do ativo a melhor firma foi a Tegma e a LLX manteve seu resultado insatisfatório neste índice de rentabilidade. Pelo prisma dos indicadores de mercado no período 2008, a Trevisa foi a companhia com melhor VPA, enquanto a ALL e a LLX apresentavam baixos VPA's e, a LLX.

Delineada esta tela, verifica-se que em cada grupo de indicadores algumas firmas obtiveram resultados mais significativos, sendo destaque no ano de 2008 a Log In, por resultados expressivos em liquidez, imobilização e resultados, bem como a Wilson nos indicadores de liquidez. Em contrapartida, a LLX já apresentava ínfimos indicadores de rentabilidade e mercado, apesar de que os baixos níveis de imobilização e resultados intermediários de liquidez poderia, numa análise geral de todos os indicadores, deixar a firma em uma condição não tão ruim assim.

Atendo-se aos resultados da ACP para o ano de 2008 temos conforme a Tabela 5 indica que as quatro componentes principais (cujo autovalor correspondente foram maior do que 1) explicaram em conjunto aproximadamente $88 \%$ da variação do sistema. Apenas as componentes 1 e 2 explicaram aproximadamente $65 \%$ de toda variação.

Tabela 5 - Autovalores e Proporção Explicada - Análise de Componentes Principais em 2008

\begin{tabular}{l|r|r|r}
\hline \multicolumn{1}{c|}{ Componente } & \multicolumn{1}{|c|}{ Autovalor } & \multicolumn{1}{c}{$\begin{array}{c}\text { Proporçáo } \\
\text { Explicada }\end{array}$} & $\begin{array}{c}\text { Proporçáo Explicada } \\
\text { Acumulada }\end{array}$ \\
\hline Componente 1 & 5,41 & $38,65 \%$ & $38,65 \%$ \\
\hline Componente 2 & 3,67 & $26,25 \%$ & $64,90 \%$ \\
\hline Componente 3 & 2,13 & $15,19 \%$ & $80,09 \%$ \\
\hline Componente 4 & 1,16 & $8,27 \%$ & $88,37 \%$ \\
\hline Componente 5 & 0,65 & $4,66 \%$ & $93,03 \%$ \\
\hline Componente 6 & 0,56 & $4,03 \%$ & $97,06 \%$ \\
\hline
\end{tabular}




\begin{tabular}{l|r|r|r}
\hline \multicolumn{1}{c|}{ Componente } & \multicolumn{1}{|c|}{ Autovalor } & \multicolumn{1}{c|}{$\begin{array}{c}\text { Proporçáo } \\
\text { Explicada }\end{array}$} & $\begin{array}{c}\text { Proporção Explicada } \\
\text { Acumulada }\end{array}$ \\
\hline Componente 7 & 0,25 & $1,81 \%$ & $98,87 \%$ \\
\hline Componente 8 & 0,10 & $0,69 \%$ & $99,57 \%$ \\
\hline Componente 9 & 0,05 & $0,38 \%$ & $99,95 \%$ \\
\hline Componente 10 & 0,01 & $0,04 \%$ & $99,99 \%$ \\
\hline Componente 11 & 0,00 & $0,01 \%$ & $100,00 \%$ \\
\hline
\end{tabular}

Fonte: Resultados da Pesquisa, 2019.

Ressaltando que dados os pressupostos da ACP as cargas fatoriais alcançam no máximo o valor 1 podemos perceber, conforme a Tabela 6 , que a primeira componente principal é dominada pelas variáveis demonstrativas de liquidez (LC, LS e LI) e em um sentido oposto, dado os sinais trocados, pelas variáveis demonstrativas de estrutura (Part K3, IPL e INRC). A segunda componente principal é dominada pelas variáveis demonstrativas de rentabilidade, RA e RPL; a terceira componente principal é dominada pela variável CE e em um sentido oposto pela variável VPA e a quarta componente principal é dominada pela variável GA.

Tabela 6 - Cargas Fatoriais das Variáveis nas Quatro Primeiras Componentes Principais em 2008

\begin{tabular}{c|c|c|c|c}
\hline Variável & Componente 1 & Componente 2 & Componente 3 & Componente 4 \\
\hline LC & 0,39 & $-0,01$ & 0,23 & 0,14 \\
\hline LS & 0,40 & 0,01 & 0,21 & 0,16 \\
\hline LI & 0,37 & $-0,09$ & 0,19 & 0,34 \\
\hline LG & 0,40 & 0,09 & $-0,11$ & 0,09 \\
\hline Part.k3 & $-0,31$ & 0,06 & 0,20 & 0,35 \\
\hline IPL & $-0,36$ & 0,16 & 0,23 & 0,23 \\
\hline CE & 0,13 & 0,20 & $-0,58$ & $-0,12$ \\
\hline IRNC & $-0,31$ & 0,28 & 0,00 & 0,03 \\
\hline GA & 0,14 & 0,24 & 0,04 & $-0,61$ \\
\hline ML & $-0,02$ & 0,35 & 0,35 & $-0,17$ \\
\hline RA & 0,12 & 0,50 & 0,02 & 0,02 \\
\hline RPL & 0,00 & 0,51 & 0,02 & 0,12 \\
\hline VPA & 0,06 & $-0,03$ & 0,54 & $-0,38$ \\
\hline LPA & 0,13 & 0,38 & $-0,10$ & 0,27 \\
\hline
\end{tabular}

Fonte: Resultados da Pesquisa, 2019.

Multiplicando-se os valores dispostos na Tabela 6 das cargas de cada componente principal pelos respectivos valores amostrais dispostos na Tabela 4 geramos os scores para as quatro primeiras componentes principais e, em sequência, o Gráfico 1. Neste 
contexto, considerando-se o score gerado pela primeira componente principal, destaca-se o desempenho das empresas Log In e Wilson Sons, o que é coerente com uma melhor situação de liquidez, conforme destacado na análise dos indicadores contábeis de 2008. Considerando-se o score gerado pela componente principal 2, destacam-se o desempenho da CCR e, em um sentido oposto, Trevisa e LLX, o que também está de acordo com a análise dos indicadores contábeis no que diz respeito à rentabilidade. Baseado no score gerado pela terceira componente principal, tem melhores resultados as empresas Trevisa, Arteris e Wilson Sons e, um sentido oposto, a LLX. Dado o peso e o sinal negativo da variável CE ressalta-se, assim como em relação ao componente 2 , o desempenho negativo desta empresa. Já, a partir do score gerado pela quarta componente principal, apresenta melhor performance as empresas ALL, Arteris e Trevisa. Considerando que as cargas fatoriais das variáveis de maior peso nesta componente (respectivamente GA e VPA) possuem sinal negativo, o score alto alcançado pela ALL, a partir deste componente, pode indicar um baixo giro do ativo e baixo valor patrimonial da ação.

Gráfico 1 - Scores dos 4 Primeiros Componentes Principais em 2008

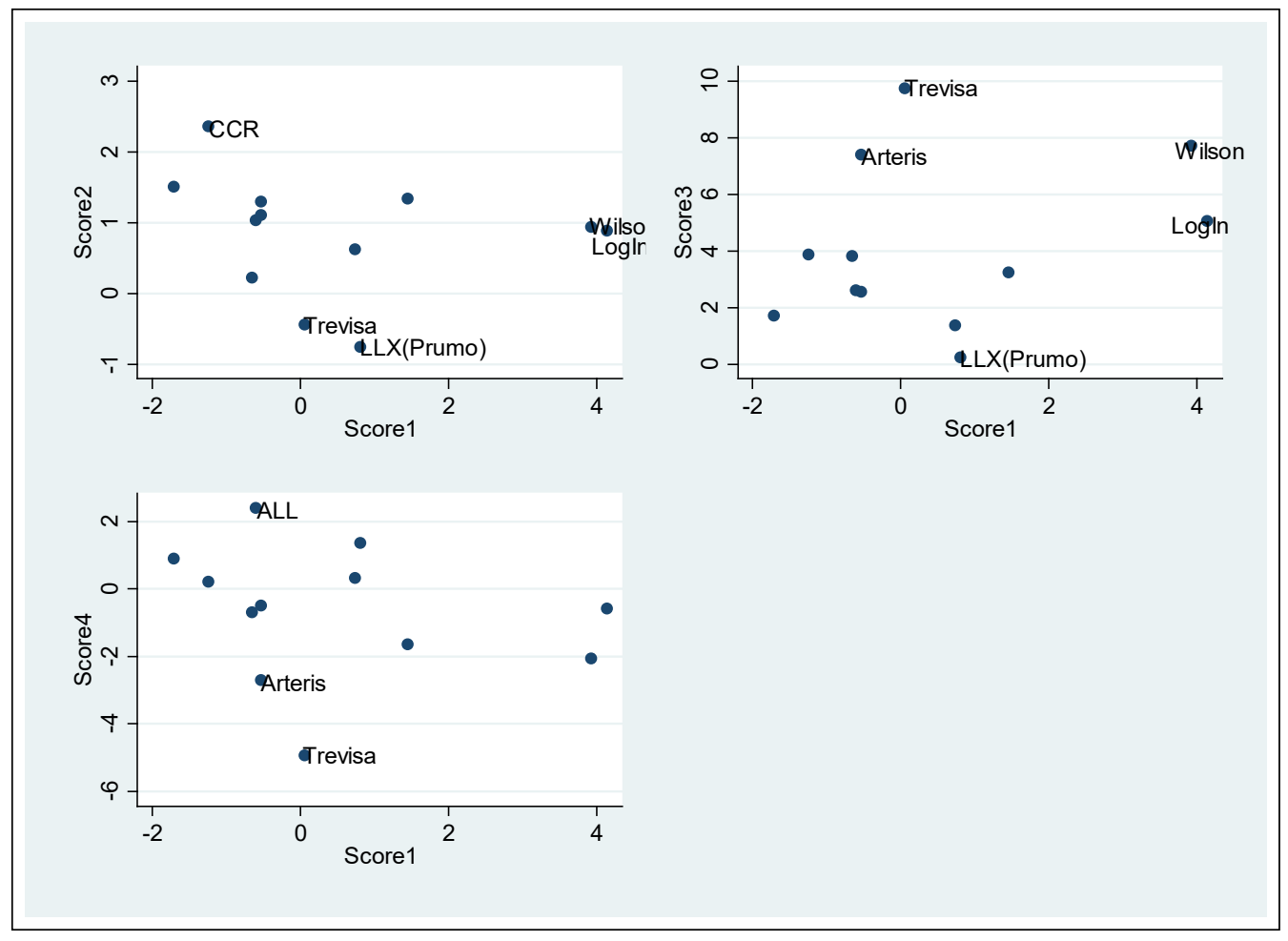

Fonte: Resultados da Pesquisa, 2019.

Lançando luz aos indicadores de 2012 para fins comparativos, conforme aponta a Tabela 7, nota-se, no que compete a análise estrita de liquidez, que a CCR é a empresa com os piores indicadores, sendo superada pela companhia Triunfo quando abordada a liquidez 
geral. Por outra perspectiva, a Wilson Sons e a ALL demonstram ótima capacidade de liquidez e a soma de seus ativos supera de forma substancial seus passivos.

A Trevisa, de forma geral, foi à firma com melhores indicadores de estrutura de capital enquanto pelo vértice de análise da rentabilidade, a LLX apresentou os piores resultados enquanto a CCR e a Triunfo apresentaram índices satisfatórios de rentabilidade do patrimônio líquido, do ativo e alta margem líquida. No que diz respeito ao indicadores de mercado, há forte destacam-se a Trevisa e Wilson, enquanto LLX e Log In não apresentaram bons resultados nesses índices.

É importante ressaltar que o índice preço lucro, por refletir o número de anos necessários para o retorno em dividendos do capital investido, pode sofrer distorçóes pois, determinada empresa pode estar empenhada em investir no seu próprio negócio gerando no final do período um lucro negativo.

Tabela 7: Indicadores Fundamentalistas para 2012

\begin{tabular}{c|c|c|c|c|c|c|c|c|c|c|c|c|c|c}
\hline Empresas & LC & LS & LI & LG & Part k 3 & IPL & $\begin{array}{c}\text { Comp. } \\
\text { Endi }\end{array}$ & IRNC & GA & ML & RA & RPL & VPA & LPA \\
\hline ALL & 1,48 & 1,42 & 1,01 & 0,39 & 3,18 & 2,96 & 0,19 & 0,82 & 0,22 & 0,07 & 0,02 & 0,06 & 6,11 & 0,36 \\
\hline Arteris & 0,86 & 0,85 & 0,65 & 0,25 & 2,76 & 3,08 & 0,24 & 0,99 & 0,54 & 0,13 & 0,07 & 0,27 & 4,67 & 1,58 \\
\hline CCR & 0,43 & 0,43 & 0,23 & 0,45 & 3,31 & 2,82 & 0,34 & 0,89 & 0,38 & 0,23 & 0,09 & 0,36 & 1,90 & 0,68 \\
\hline JSL & 1,23 & 1,07 & 0,29 & 0,46 & 3,81 & 3,08 & 0,31 & 0,85 & 0,96 & 0,02 & 0,02 & 0,09 & 4,38 & 0,36 \\
\hline LLX (Prumo) & 0,84 & 0,84 & 0,36 & 0,59 & 3,09 & 2,36 & 0,49 & 0,92 & 0,02 & $-0,53$ & $-0,01$ & $-0,04$ & 1,26 & $-0,05$ \\
\hline Log In & 1,18 & 1,15 & 0,38 & 0,40 & 2,57 & 2,54 & 0,18 & 0,82 & 0,41 & $-0,03$ & $-0,01$ & $-0,05$ & 5,79 & $-0,29$ \\
\hline SBP & 0,87 & 0,82 & 0,38 & 0,60 & 0,60 & 1,24 & 0,44 & 0,93 & 0,49 & 0,09 & 0,04 & 0,08 & 2,06 & 0,22 \\
\hline Triunfo & 0,73 & 0,73 & 0,32 & 0,14 & 1,78 & 1,79 & 0,12 & 0,70 & 0,22 & 0,55 & 0,12 & 0,32 & 12,63 & 3,53 \\
\hline Ecorodovias & 0,91 & 0,91 & 0,66 & 0,38 & 1,93 & 2,21 & 0,35 & 0,98 & 0,47 & 0,18 & 0,08 & 0,21 & 3,77 & 0,76 \\
\hline Tegma & 1,30 & 1,30 & 0,03 & 0,92 & 1,60 & 1,11 & 0,64 & 0,70 & 1,76 & 0,04 & 0,08 & 0,19 & 6,43 & 1,21 \\
\hline Wilson & 1,60 & 1,47 & 0,67 & 0,50 & 1,51 & 1,76 & 0,28 & 0,84 & 0,56 & 0,07 & 0,04 & 0,10 & 14,31 & 1,37 \\
\hline Trevisa & 1,06 & 1,02 & 0,60 & 0,85 & 0,67 & 1,10 & 0,15 & 0,70 & 0,35 & 0,09 & 0,03 & 0,06 & 47,33 & 2,57 \\
\hline
\end{tabular}

Fonte: Resultados da Pesquisa, 2019.

Atendo-se aos resultados da ACP para o ano de 2012 temos, de acordo com a Tabela 8 , que as cinco componentes principais (cujo autovalor correspondente foram maior do que 1) explicaram em conjunto aproximadamente $93 \%$ da variação do sistema. As componentes 1 e 2 explicaram aproximadamente $56 \%$ de toda variação, valor menor do que observado em 2008. 
Tabela 8 - Autovalores e Proporção Explicada - Análise de Componentes Principais em 2012

\begin{tabular}{c|c|c|c}
\hline Componente & Autovalor & Proporção Explicada & $\begin{array}{c}\text { Proporção Explicada } \\
\text { Acumulada }\end{array}$ \\
\hline Componente 1 & 4,03 & $28,82 \%$ & $28,82 \%$ \\
\hline Componente 2 & 3,77 & $26,93 \%$ & $55,75 \%$ \\
\hline Componente 3 & 2,72 & $19,45 \%$ & $75,20 \%$ \\
\hline Componente 4 & 1,55 & $11,09 \%$ & $86,29 \%$ \\
\hline Componente 5 & 0,95 & $6,76 \%$ & $93,05 \%$ \\
\hline Componente 6 & 0,47 & $3,35 \%$ & $96,40 \%$ \\
\hline Componente 7 & 0,27 & $1,92 \%$ & $98,32 \%$ \\
\hline Componente 8 & 0,17 & $1,24 \%$ & $99,56 \%$ \\
\hline Componente 9 & 0,03 & $0,25 \%$ & $99,81 \%$ \\
\hline Componente 10 & 0,02 & $0,12 \%$ & $99,93 \%$ \\
\hline Componente 11 & 0,01 & $0,07 \%$ & $100,00 \%$ \\
\hline
\end{tabular}

Fonte: Resultados da Pesquisa, 2019.

A Tabela 9 indica que a primeira componente principal em 2012 foi dominada pelas variáveis demonstrativas de rentabilidade (ML, RA e RPL) e pela variável indicativa de mercado LPA. Dado o sinal positivo, espera-se que valores altos para o score gerado pela componente 1 indiquem uma situação favorável da empresa. A segunda componente principal é dominada pelas variáveis demonstrativas de estrutura (Partk3, IPL e IRNC) com sinal negativo e liquidez (LC, LS e LG) com sinal positivo. A terceira componente principal é dominada pela variável $\mathrm{CE}$, a quarta componente principal é dominada pelas variáveis LC, LS e GA, enquanto a quinta componente principal é dominada pela variável IRNC e, em um sentido oposto, Part.k3.

Tabela 9 - Cargas Fatoriais das Variáveis nas Cinco Primeiras Componentes Principais de 2012

\begin{tabular}{c|c|c|c|c|c}
\hline Variável & Componente 1 & Componente 2 & Componente 3 & Componente 4 & Componente 5 \\
\hline LC & $-0,25$ & 0,28 & 0,23 & 0,43 & 0,10 \\
\hline LS & $-0,25$ & 0,29 & 0,22 & 0,43 & 0,13 \\
\hline LI & $-0,10$ & $-0,08$ & 0,49 & 0,05 & 0,45 \\
\hline LG & $-0,12$ & 0,40 & $-0,23$ & $-0,18$ & $-0,03$ \\
\hline Part.k3 & $-0,18$ & $-0,36$ & $-0,04$ & 0,26 & $-0,47$ \\
\hline IPL & $-0,15$ & $-0,43$ & 0,10 & 0,24 & $-0,24$ \\
\hline CE & $-0,14$ & 0,12 & $-0,53$ & 0,02 & 0,22 \\
\hline IRNC & $-0,15$ & $-0,36$ & $-0,09$ & $-0,11$ & 0,57 \\
\hline GA & 0,00 & 0,25 & $-0,35$ & 0,48 & $-0,04$ \\
\hline
\end{tabular}




\begin{tabular}{c|c|c|c|c|c}
\hline Variável & Componente 1 & Componente 2 & Componente 3 & Componente 4 & Componente 5 \\
\hline ML & 0,43 & $-0,02$ & 0,13 & 0,26 & 0,07 \\
\hline RA & 0,45 & $-0,04$ & $-0,14$ & 0,20 & 0,22 \\
\hline RPL & 0,41 & $-0,16$ & $-0,15$ & 0,23 & 0,09 \\
\hline VPA & 0,14 & 0,32 & 0,31 & $-0,26$ & $-0,20$ \\
\hline LPA & 0,42 & 0,15 & 0,18 & 0,01 & $-0,11$ \\
\hline
\end{tabular}

Fonte: Resultados da Pesquisa, 2019.

A partir do Gráfico 2, considerando-se os scores gerados pela primeira e segunda componentes principais, destaca-se o desempenho da empresa Trevisa, o que é coerente com uma situação favorável de rentabilidade e mercado (considerando a componente 1) e estrutura dado o sinal negativo das variáveis Part.k3, IPL e IRNC que possuem um grande peso na segunda componente principal. No entanto, quando analisamos o score gerado pela terceira componente principal dominadas pelas variáveis CE e GA, ambas com sinal negativo, temos a indicação de uma composição do endividamento desfavorável, o que pode ser compensado por um alto giro do ativo e reforçado por um baixo valor patrimonial da ação.

O desempenho da Trevisa avaliado pelo score da quarta e quinta componentes principais destacam a necessidade de precaução com a liquidez e reforçam a dificuldade com giro do ativo e participação com capital de terceiros, mas indicam também um índice baixo para imobilização de recursos não correntes. As demais companhias amostradas não apresentaram variaçóes significativas em relação ao conjunto dos dados para o ano de 2012, exceto Wilson Sons e Triunfo que apresentaram um score calculado a partir da primeira componente principal um pouco acima da média do grupo. 
Gráfico 2 - Scores dos 5 Primeiros Componentes Principais em 2012

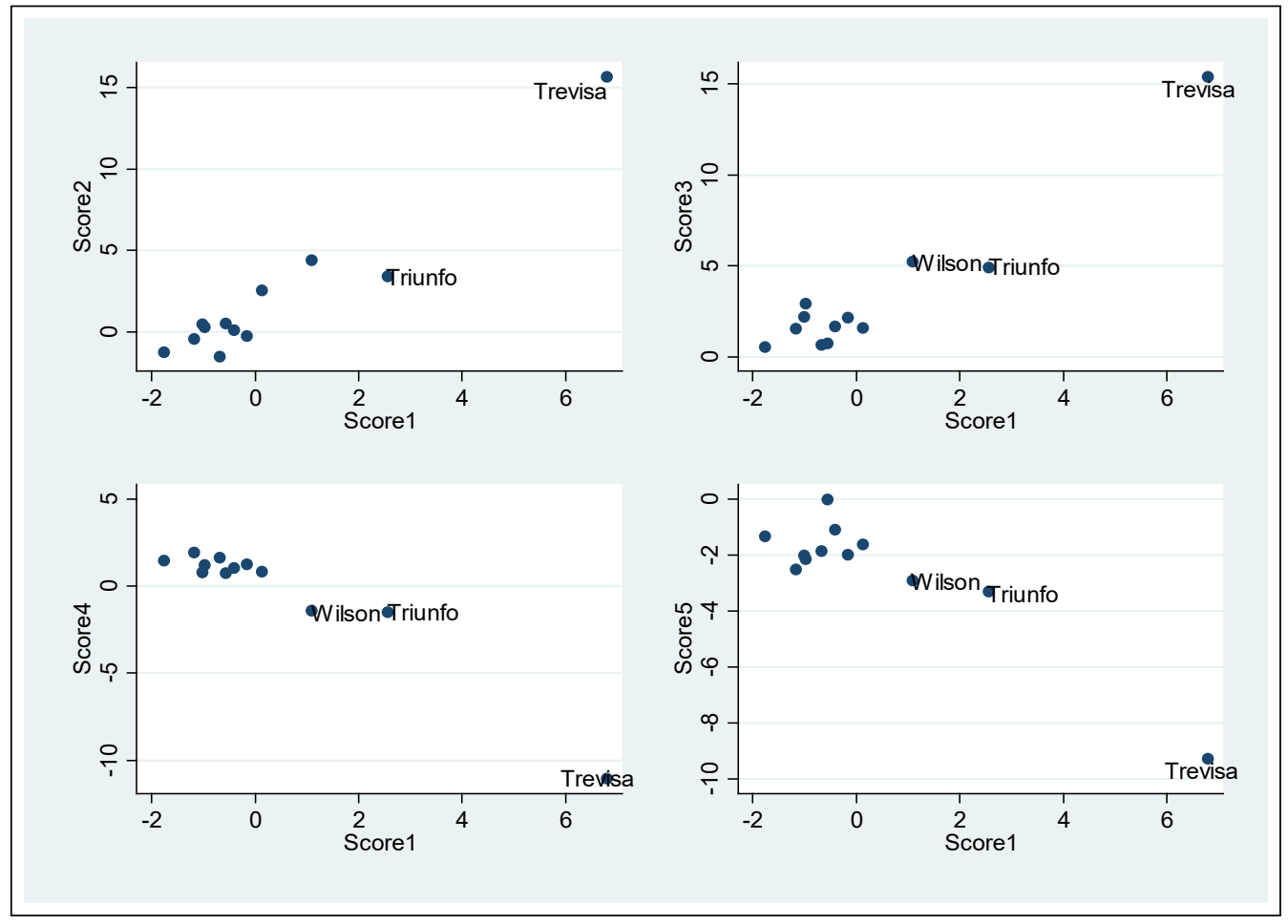

Fonte: Resultados da Pesquisa, 2019.

Dada a conformidade entre a análise dos índices contábeis e a ACP para os anos de 2008 e 2012 a análise a seguir, considerando-se os anos de 2015 e 2017, irá basear-se somente na ACP, já que o propósito deste artigo é justamente propor a simplificação da análise fundamentalista, principalmente no que concerne a massa de dados utilizada neste tipo de análise por meio de indicadores.

Sendo assim, podemos observar na Tabela 10 que as quatro primeiras componentes principais explicam em conjunto aproximadamente $92 \%$ de toda a variação do sistema em 2015. Note-se, portanto, que a primeira componente principal explicou quase a metade de toda a variação do sistema.

Tabela 10 - Autovalores e Proporção Explicada - Análise de Componentes Principais em 2015

\begin{tabular}{c|c|c|c}
\hline Componente & Autovalor & Proporção Explicada & $\begin{array}{c}\text { Proporção Explicada } \\
\text { Acumulada }\end{array}$ \\
\hline Componente 1 & 6,95 & $49,65 \%$ & $49,65 \%$ \\
\hline Componente 2 & 3,54 & $25,27 \%$ & $74,92 \%$ \\
\hline Componente 3 & 1,59 & $11,34 \%$ & $86,26 \%$ \\
\hline
\end{tabular}




\begin{tabular}{c|c|c|c}
\hline Componente & Autovalor & Proporção Explicada & $\begin{array}{c}\text { Proporção Explicada } \\
\text { Acumulada }\end{array}$ \\
\hline Componente 4 & 0,83 & $5,90 \%$ & $92,16 \%$ \\
\hline Componente 5 & 0,62 & $4,44 \%$ & $96,60 \%$ \\
\hline Componente 6 & 0,35 & $2,48 \%$ & $99,08 \%$ \\
\hline Componente 7 & 0,07 & $0,49 \%$ & $99,57 \%$ \\
\hline Componente 8 & 0,05 & $0,36 \%$ & $99,93 \%$ \\
\hline Componente 9 & 0,01 & $0,07 \%$ & $100,00 \%$ \\
\hline Componente 10 & 0,00 & $0,00 \%$ & $100,00 \%$ \\
\hline Componente 11 & 0,00 & $0,00 \%$ & $100,00 \%$ \\
\hline
\end{tabular}

Fonte: Resultados da Pesquisa, 2019.

Neste flanco analítico, conforme indica a Tabela 11, a primeira componente principal é dominada pelas variáveis do grupo liquidez e a variável LPA, com sinal negativo, bem como as variáveis de estrutura e rentabilidade com sinal positivo, sem uma dominância clara de nenhuma delas. Assim, o entendimento do desempenho das empresas a partir desta componente torna-se opaco e dificultado. A segunda componente principal é dominada pelas variáveis de rentabilidade e VPA, o que indica que valores altos a partir do score gerado por esta componente indicam uma situação favorável da empresa. A terceira componente principal está relacionada ao grupo de liquidez e do VPA com sinal negativo ao passo que a quarta componente principal é amplamente dominada pela variável LG.

Tabela 11 - Cargas Fatoriais das Variáveis nas Quatro Primeiras Componentes Principais de 2015

\begin{tabular}{c|c|c|c|c}
\hline Variável & Componente 1 & Componente 2 & Componente 3 & Componente 4 \\
\hline LC & $-0,31$ & $-0,04$ & 0,40 & 0,06 \\
\hline LS & $-0,31$ & $-0,06$ & 0,39 & 0,03 \\
\hline LI & $-0,34$ & $-0,14$ & 0,22 & 0,09 \\
\hline LG & $-0,16$ & 0,20 & 0,17 & 0,82 \\
\hline Part.k3 & 0,27 & $-0,33$ & 0,01 & 0,12 \\
\hline IPL & 0,28 & $-0,33$ & $-0,02$ & 0,14 \\
\hline CE & 0,31 & $-0,15$ & 0,20 & 0,20 \\
\hline IRNC & 0,29 & $-0,29$ & $-0,07$ & 0,28 \\
\hline GA & $-0,29$ & $-0,25$ & 0,01 & $-0,14$ \\
\hline ML & 0,22 & 0,40 & 0,21 & $-0,10$ \\
\hline RA & 0,26 & 0,35 & 0,24 & $-0,03$ \\
\hline RPL & 0,23 & 0,39 & 0,24 & $-0,09$ \\
\hline VPA & $-0,05$ & 0,29 & $-0,47$ & 0,35 \\
\hline LPA & $-0,28$ & 0,18 & $-0,44$ & $-0,01$ \\
\hline
\end{tabular}

Fonte: Resultados da Pesquisa, 2019. 
Dada as considerações acima, é possível inferir, conforme o Gráfico 3, o desempenho destacado da Log In no que se refere tanto a primeira quanto a segunda componente principal, situando-se respectivamente acima e abaixo da média do grupo. A análise da primeira componente, como destacado, foi dificultada uma vez que nenhuma variável (ou grupo de análise) apresentou dominância significativa, além dos sinais trocados. Assim uma análise mais minuciosa do balanço torna-se necessária.

Por outro lado, o desempenho da Log In a partir do score gerado pela segunda componente principal indica uma composição de capital adequada, mas uma rentabilidade abaixo da média amostral. A análise para a Trevisa considerando-se a segunda componente principal é exatamente oposta. Da mesma maneira Trevisa e Log In apresentam desempenho opostos ao considerarmos a terceira componente principal.

Neste caso, dada a dominância das variáveis pertinentes ao grupo de liquidez e rentabilidade com sinal positivo e mercado com sinal negativo torna pouco conclusiva a análise sobre o desempenho destas empresas. A análise da quarta componente principal aponta para um desempenho superior da Trevisa no quesito liquidez geral.

Gráfico 3 - Scores dos 4 Primeiros Componentes Principais em 2015

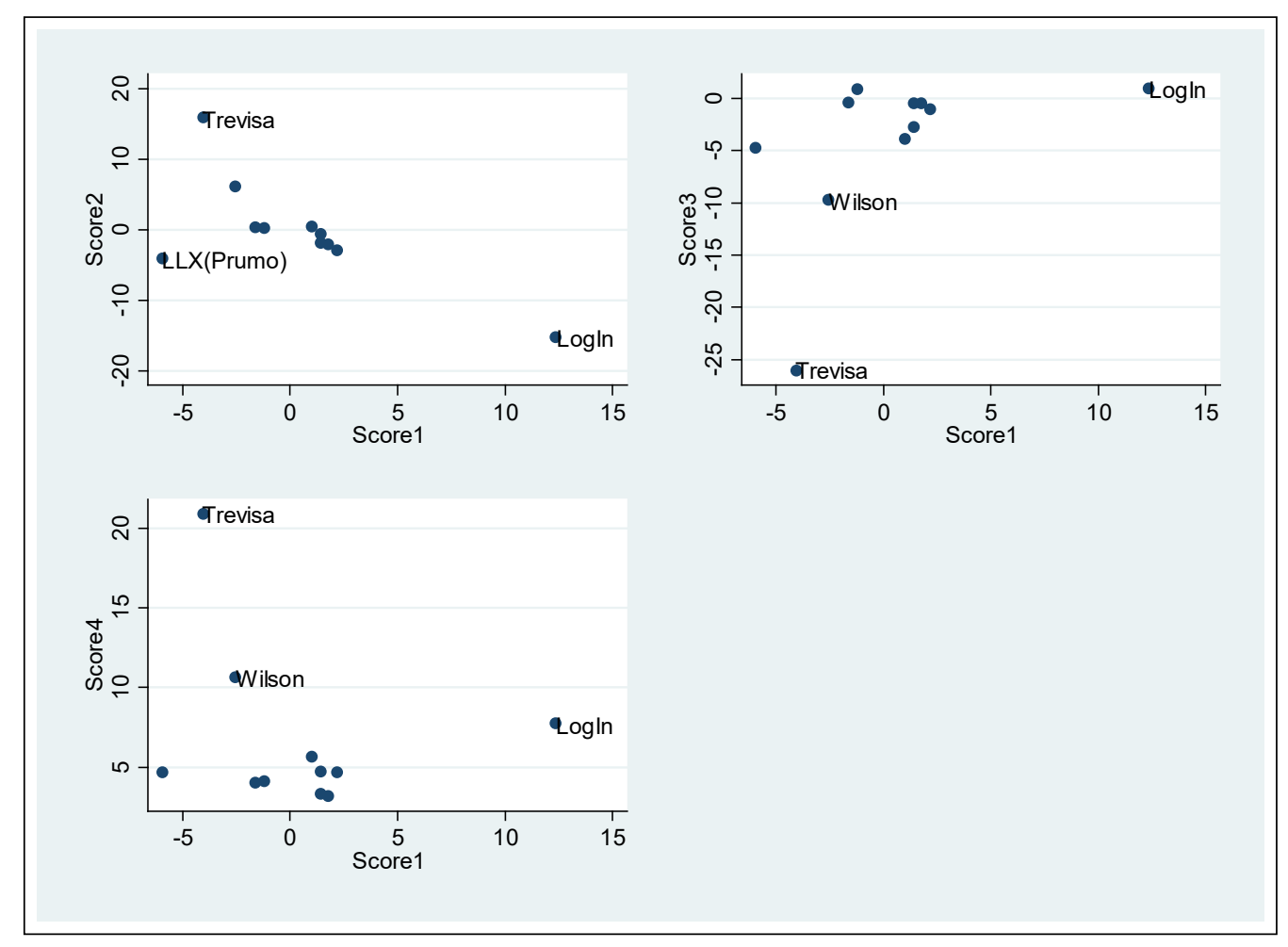

Fonte: Resultados da Pesquisa, 2019.

A Tabela 12 indica que as cinco primeiras componentes principais explicaram em conjunto aproximadamente $93 \%$ de toda a variaçáo do sistema em 2017. Além disso, 
note-se que a primeira e segunda componentes principais explicam mais de $55 \%$ de toda a variação do sistema.

Tabela 12 - Autovalores e Proporção Explicada - Análise de Componentes Principais em 2017

\begin{tabular}{l|c|c|c}
\hline \multicolumn{1}{c|}{ Componente } & Autovalor & $\begin{array}{c}\text { Proporção } \\
\text { Explicada }\end{array}$ & $\begin{array}{c}\text { Proporçáo Explicada } \\
\text { Acumulada }\end{array}$ \\
\hline Componente 1 & 5,28 & $37,68 \%$ & $37,68 \%$ \\
\hline Componente 2 & 2,50 & $17,86 \%$ & $55,54 \%$ \\
\hline Componente 3 & 2,30 & $16,44 \%$ & $71,98 \%$ \\
\hline Componente 4 & 1,78 & $12,69 \%$ & $84,66 \%$ \\
\hline Componente 5 & 1,22 & $8,74 \%$ & $93,41 \%$ \\
\hline Componente 6 & 0,36 & $2,56 \%$ & $95,91 \%$ \\
\hline Componente 7 & 0,28 & $2,02 \%$ & $97,98 \%$ \\
\hline Componente 8 & 0,16 & $1,13 \%$ & $99,11 \%$ \\
\hline Componente 9 & 0,11 & $0,79 \%$ & $99,90 \%$ \\
\hline Componente 10 & 0,01 & $0,09 \%$ & $99,99 \%$ \\
\hline Componente 11 & 0,00 & $0,01 \%$ & $100,00 \%$ \\
\hline
\end{tabular}

Fonte: Resultados da Pesquisa, 2019.

Por meio da Tabela 13 percebe-se a dominância das variáveis LC, LS e GA, com sinal negativo e as demais do grupo de rentabilidade com sinal positivo no que concerne à primeira componente principal. A segunda componente principal apresenta uma clara dominância das variáveis LI e LG, a terceira componente principal é dominada pelas variáveis Part.k3 e IPL, a quarta componente é dominada pelas variáveis de mercado e a quinta pela componente VPA com sinal negativo e CE com sinal positivo.

Tabela 13 - Cargas Fatoriais das Variáveis nas Quatro Primeiras Componentes Principais de 2017

\begin{tabular}{c|c|c|c|c|c}
\hline Variável & Componente 1 & Componente 2 & Componente 3 & Componente 4 & Componente 5 \\
\hline LC & $-0,34$ & 0,29 & 0,11 & $-0,21$ & $-0,01$ \\
\hline LS & $-0,35$ & 0,28 & 0,10 & $-0,20$ & 0,00 \\
\hline LI & $-0,12$ & 0,51 & 0,09 & $-0,01$ & 0,23 \\
\hline LG & 0,01 & 0,44 & $-0,29$ & 0,27 & 0,18 \\
\hline Part.k3 & 0,01 & 0,00 & 0,64 & 0,14 & 0,00 \\
\hline IPL & 0,03 & $-0,03$ & 0,63 & 0,17 & 0,02 \\
\hline CE & 0,26 & 0,20 & $-0,10$ & 0,20 & 0,55 \\
\hline IRNC & 0,24 & $-0,29$ & 0,01 & 0,37 & 0,33 \\
\hline GA & $-0,40$ & $-0,12$ & $-0,10$ & 0,12 & 0,11 \\
\hline
\end{tabular}




\begin{tabular}{c|c|c|c|c|c}
\hline Variável & Componente 1 & Componente 2 & Componente 3 & Componente 4 & Componente 5 \\
\hline ML & 0,38 & 0,27 & 0,09 & $-0,09$ & $-0,12$ \\
\hline RA & 0,39 & 0,23 & 0,06 & $-0,17$ & $-0,12$ \\
\hline RPL & 0,38 & 0,18 & 0,02 & $-0,28$ & $-0,12$ \\
\hline VPA & 0,07 & 0,10 & $-0,19$ & 0,41 & $-0,65$ \\
\hline LPA & $-0,13$ & 0,28 & 0,10 & 0,57 & $-0,17$ \\
\hline
\end{tabular}

Fonte: Resultados da Pesquisa, 2019.

Dadas as consideraçóes tecidas acima, podemos inferir, ao analisarmos o Gráfico 4, um desempenho diferenciado da LLX (Prumo) no que diz respeito à primeira e segunda componente principal. Isso pode indicar um desempenho inadequado em termos de liquidez e rentabilidade.

Gráfico 4: Scores dos 5 Primeiros Componentes Principais em 2017

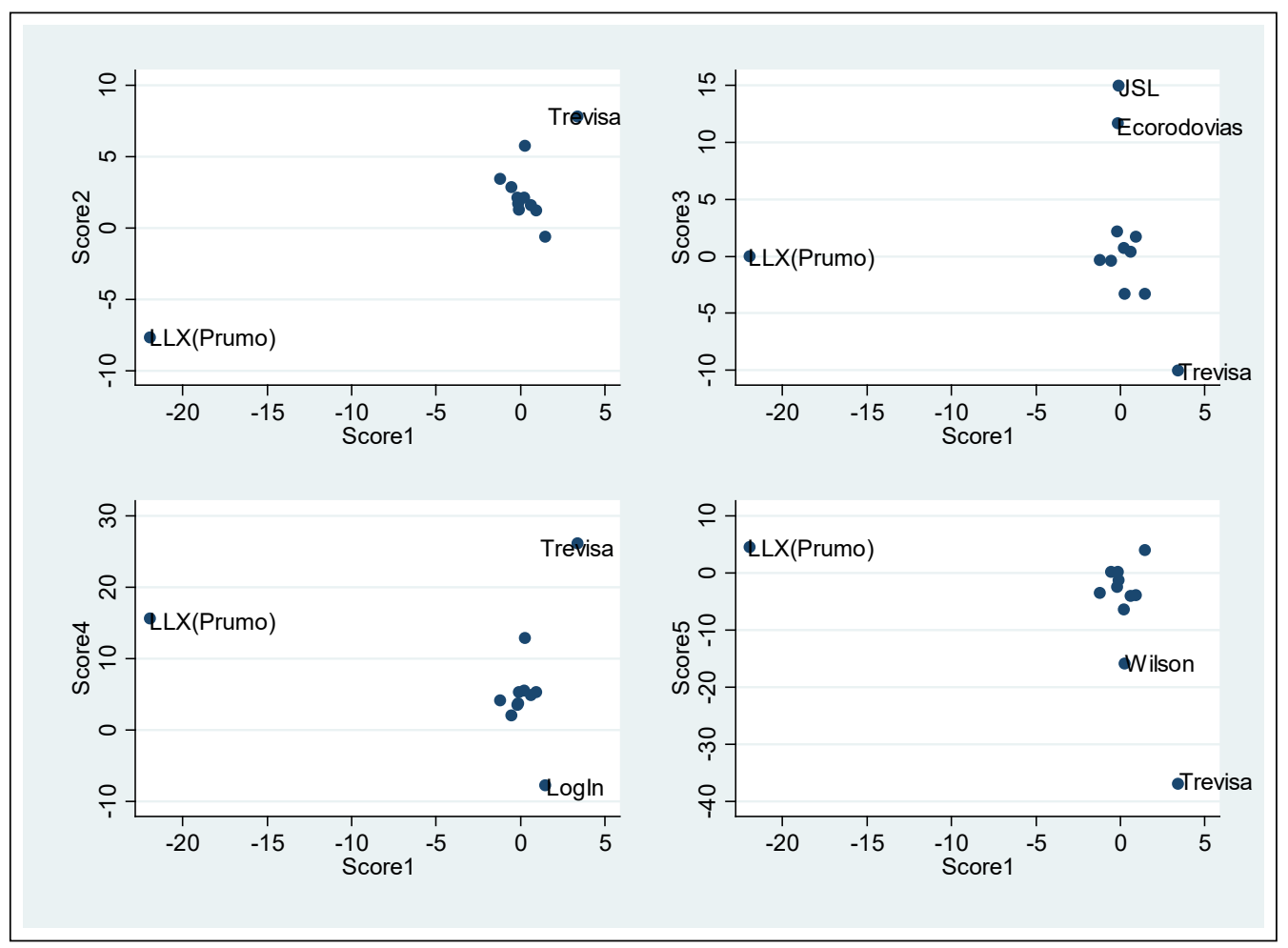

Fonte: Resultados da Pesquisa, 2019

Em outro sentido e ainda em consonância com o Gráfico 4, conclui-se que Trevisa apresentou um desempenho um pouco acima da média considerando-se a segunda componente, indicando situaçáo favorável no que se refere à liquidez e rentabilidade. A análise da terceira componente principal indica que a JSL a Ecorodovias e a Trevisa apresentam uma composição de capital diferenciada em relação às demais empresas do 
setor de transportes. A análise da quarta componente principal indica que a Trevisa e Log In apresentam desempenhos díspares no que concerne às variáveis de mercado. A análise da quinta componente principal indica desempenhos opostos da Trevisa e LLX (Prumo) no que diz respeito à composiçáo do endividamento e VPA, sendo que a primeira apresenta uma situação mais desfavorável.

\section{Consideraçóes Finais}

Em traço geral, sabe-se que análise fundamentalista é crucial para compreender a situação econômica, financeira e patrimonial de qualquer firma, sendo esta técnica largamente utilizada por acadêmicos, analistas e investidores. Nesse contexto, por meio do cálculo de um número consubstancial de índices pode-se compreender os fundamentos de empresas distintas, seja pelo enfoque de liquidez e endividamento, ou rentabilidade e mercado, e realizar comparaçóes de uma amostra de empresas.

No entanto, a análise fundamentalista implica em certa subjetividade, pois as variáveis em destaque dependem do julgamento do analista, isto é, conforme seu padrão de decisão pode-se privilegiar empresas com baixo endividamento em detrimento de empresas com alto grau de alavancagem e expressiva rentabilidade, por exemplo, além de ter que utilizar várias variáveis nos momentos de análise e decisão investimento, na oportunidade 14 variáveis para cada empresa ao longo da série 2008-2017.

Neste contexto, este trabalho representou uma construção de um esforço metodológico no sentido aprimorar a análise dos indicadores contábeis das empresas, diminuir decisôes centradas no juízo de valor dos analistas e contribuir para a identificação de padrôes discrepantes de determinada empresa em relação a seu grupo. Portanto, os resultados alcançados demonstram que a técnica da ACP é extremamente útil para esta finalidade, uma vez que permite reduzir a massa de dados que será utilizada no processo decisório, mitigar o grau de subjetividade do analista e simplificar os procedimentos de análise financeira.

Deve-se ressaltar, portanto, que a análise fundamentalista e aCP devem ser realizadas de maneira complementar. Propóe-se como metodologia assim identificar inicialmente os padróes discrepantes por meio da ACP e em um segundo momento realizar uma análise mais minuciosa por meio da análise fundamentalista. A observação de vários anos amostrais favorece a compreensão de um quadro mais detalhado.

Contudo, a escolha do setor de transportes dificultou substancialmente a análise, pois ao selecionar uma amostra que abarca empresas que ofertam serviços díspares - tais como transporte ferroviário e concessōes rodoviárias -, sendo que cada um destes serviços requer níveis de "capital imobilizado" diferenciados, lidou com firmas que enfrentam graus de concorrência distintos e, consequentemente, elasticidades no preço da demanda que também variam significativamente de empresa para empresa.

Ademais, esta pesquisa contribui para uma compreensão mais ampla acerca da capacidade financeira das firmas e os resultados gerados estão em perfeita consonância com eventos recentes ocorridos no cenário econômico envolvendo essas mesmas empresas, principalmente aqueles evidenciados no mercado de capitais. 
Como agenda de pesquisa propóe-se analisar, conjuntamente, distintos setores econômicos e comparar os resultados obtidos com a evolução temporal no preço das açóes das companhias em questáo. Dessa maneira, buscar-se-á compreender se as informaçóes contábeis efetivamente norteiam a tomada de decisão por parte dos agentes, como apregoa a teoria dos mercados eficientes. Além disso, para trabalhos futuros sugere-se também a utilização de uma série temporal maior e a ampliação do número de variáveis utilizadas, englobando, por exemplo, indicadores de atividade.

\section{Referências}

AITCHISON, J. The statistical analysis of compositional data. Chapman \& Hall, 1986

ASSAF NETO, A. Estrutura e análise de balanços: um enfoque econômico-financeiro. 10. Ed. São Paulo: Atlas, 2012.

BARBOSA NETO, J. E.; DIAS, W.O. e PINHEIRO, L.E.T. Impacto da convergência para as IFRS na análise financeira: um estudo em empresas brasileiras de capital aberto. Revista Contabilidade Vista \& Revista, Belo Horizonte, v. 20, n. 4, p. 131-153, out./dez. 2009.

BASSO, Irani Paulo; FILIPIN, Roselaine; ENDERLI, Stela Maris. Estrutura, análise e interpretação de demonstraçóes contábeis. Ijuí: ed. Unijuí, 2015.

BLANK, F.F., SAMANEZ, C.P, BAIDYAB, T.K.N. e DIAS, M.A.G. Economic valuation of a toll road concession with traffic guarantees and the abandonment option. Production, vol.26, no.1. São Paulo, Jan./Mar. 2016, Epub Nov.10, 2015. Disponível em: http:// dx.doi.org/10.1590/0103-6513.168713. Acesso em janeiro de 2019.

BROCHADO, M.R. e VASSALLO, J.M. Federal Toll Road Concession Program in Brazil: Is It Moving in the Right Direction? Journal of Infrastructure Systems, Volume 20, Issue 2 - June 2014.

CALL AO, S.; JARNE, J. I. e LAÍNEZ, J. A. Adoption of IFRS in Spain: effect on the comparability and relevance of financial reporting. Journal of Accounting, Auditing and Taxation, v. 16, n. 2, p. 148-178, 2007.

CHESNICK, D.S. Financial Management and Ratio Analysis For Cooperative Enterprises. Rural Business-Cooperative Service, U.S. Department of Agriculture, Research Report 175, January: 2000. Disponível em: <http://www.rurdev.usda.gov/ supportdocuments/RR175.pdf> Acesso em: 06 de fev 2014

CHING, H.Y., MARQUES, F. e PRADO, L. Contabilidade e Finanças para não especialistas. 3 ed. São Paulo: Pearson Prentice Hall, 2010. 
COSTA, G.G.O. Um procedimento inferencial para análise fatorial utilizando as técnicas Bootstrap e Jackknife: construção de intervalos de confiança e testes de hipóteses. Tese de Doutorado. Rio de Janeiro: PUC, Departamento de Engenharia Elétrica, 2006.

COSTA, J. P. e LOPES, P.T. O impacto da adopção das IAS/IFRS nas demonstrações financeiras das empresas cotadas na Euronext Lisboa. In: CONGRESSO DE CONTABILIDADE E AUDITORIA, 12., 2008, Aveiro/Portugal. Anais... Aveiro: 2008.

EVERITT, B. An R and S-PLUS Companion to Multivariate Analysis. Springer Texts in Statistics, London, 2005

FINANCIAL TIMES. Brazil's truckers put popular protest centre stage. São Paulo, 2 de junho de 2018. Disponível em: https:/www.ft.com/content/1a92ebbe-6522-11 e8-90c29563a0613e56. Acesso em 12 de fevereiro de 2019.

GITMAN, L. J. Princípios de Administração Financeira. 10 ed. São Paulo: Pearson, 2006.

GOLLO, V. e SILVA, T.P. Eficiência no Desempenho Econômico Financeiro de Cooperativas de Crédito Brasileiras. XXI Congresso Brasileiro de Custos. Natal, RN, Brasil, 17 a 19 de novembro de 2014. <http://www.anaiscbc.emnuvens.com.br/anais/ article/view/3682/3683> Acesso em: 18 de jul 2014

HORNE, V.J. e WACHOWICZ, J.M. Fundamentals of Financial Management. 13a ed. Financial Times Press (Prentice Hall): 2009.

HOTELLING, H. Analysis of a complex os statistical variable into principal component. Journal Educational Psychol, 1933, 24: pp.417-441;498-520.

HUYNH, K, P.;JACHO-CHÁVEZ, D, T.; PETRUNIA, R, J.; VOIA, M. Functional Principal Component Analysis of Density Families with Categorical and Continuous Data on Canadian Entrant Manufacturing Firms. Journal of the American Statistical Assotiation, v. 106, p. 858-878, 2011.

IUDÍCIBUS, S. Análise de Balanços. 10 ed. São Paulo: Atlas, 2010.

IUDÍCIBUS, S.; MARTINS, E.; KANITZ, S.; RAMOS, A.; CASTILHO, E.; BENATTI, L.; FILHO, E.; JÚNIOR, R. Contabilidade Introdutória. 11 ed. SP: Atlas, 2010.

JOHNSON, R. A. Applied Multivariate Statistical Analysis. 6 ed. Prentice Hall/Pearson: New York, 2007

KLANN, R. C.; BEUREN, I. M.; HEIN, N. Impacto das diferenças entre as Normas Brasileiras de Contabilidade e Americanas nos indicadores de desempenho de empresas brasileiras com ADRs. Brazilian Business Review, Vitoria, v. 6, n. 2, p. 154-173, mai./ago. 2009. 
LANTTO, A.M. e SAHLSTRÖM, P. Impact of International Financial Reporting Standards adoption on key financial ratios. Accounting and Finance, v. 49, p. 341-361, 2009.

LEMES, S. e CARVALHO, L. N. G. Comparabilidade entre o resultado em BR GAAP e U.S. GAAP: evidências das companhias brasileiras listadas nas bolsas norte-americanas. Revista Contabilidade \& Finanças, São Paulo, v. 20, n. 50, p. 25-45, mai./ago. 2009.

LATTIN, J; CARROL, J, D; GREEN, P, E. Análise de Dados Multivariados. Sáo Paulo: Cengage Learning, 2011.

LESÁKOVÁ, L. Uses and Limitations of Profitability Ratio Analysis in Managerial Practice. 5 ${ }^{\mathrm{a}}$ International Conference on Management, Enterprise and Benchmarking. Budapeste: Hungary, 2007, jun.1-2.

LOPES, L. F. D. Análise de componentes principais aplicada à confiabilidade de sistemas complexos. Dissertação (Mestrado em Engenharia de Produção) Programa de Pós-Graduação em Engenharia de Produção, Universidade Federal de Santa Catarina, Florianópolis, 2001.

MARION, J.C. Contabilidade Básica. 10 ed. SP: Atlas, 2010.

MATARAZZO, D. Análise financeira de balanços: abordagem básica e gerencial. 7. ed. São Paulo: Atlas, 2010.

MINGOTI, S. A. Análise de dados através de métodos de estatística multivariada: uma abordagem aplicada. Belo Horizonte: Editora UFMG, 2005.

MOROZINI, J, F; OLINQUEVITCH, J, L; HEIN, N. Seleção de Índices na Análise de Balanços: Uma Aplicação da Técnica Estatística ACP. Revista Contabilidade \& Finanças, São Paulo, n.41, p.87-99, 2006.

NETO, MOREIRA e MOTTA. Modelos de Concessão de Rodovias no Brasil, no México, no Chile, na Colômbia e nos Estados Unidos: Evolução Histórica e Avanços Regulatórios. IPEA: Texto para Discussão n. 2378. Rio de Janeiro, março de 2018.

NIEDERAUER, C., VENDRUSCOLO, M. e SALLABERRY, J. Análise das Demonstraçôes Contábeis: Um Estudo da Emissão de Açóes no Banrisul S.A. Revista de Contabilidade da UFBA, Salvador-Bahia. V. 12, N. 3, Pág. 86-110, set-dez 2018.

OLAWALE, F.; GARWE, D. Obstacles to the growth of new SMEs in South Africa: A principal component analysis approach. African Journal of Business Management, V. 4(5), p. 729-738, 2010. 
OLIVEIRA, J. C. T.; CUNHA, D. C. Panorama dos Retornos dos IPOs sob o Ponto de Vista do Investidor. Revista Catarinense da Ciência Contábil, v. 14, n. 41, p. 74-89, 2015. DOI: $10.16930 / 2237-7662 /$ rccc.v14n41p74-89.

PADOVEZE, C.L.; BENEDICTO, G.C. Análise das Demonstrações Financeiras. 3 ed. SP: Cengage Learning, 2014.

PEARSON, K. On lines and planes of closest fit to systems of points in space. Philosophical Magazine, 1901, 2: pp.559-572.

PENMAN, S. Análise de Demonstraçóes Financeiras e Security Valuation. RJ: Elsevier, 2013.

PERIASAMY, P. A Textbook of Financial, Cost and Management Accounting. Himalaya Publishing House: Mumbai, 2010.

RENCHER, A, C;. CHRISTENSEN, W, F. Methods of Multivariate Analysis. Jhon Wiley \& Sons, 3ed, 2012.

RIBEIRO, O. Contabilidade Geral Fácil. 8 ed. SP: Saraiva, 2012.

RICHARDSON, R. Jarry. Pesquisa Social: métodos e técnicas. 2. a ed. São Paulo: Atlas, 1989.

SALEEM, Q. e REHMAN, R. Impacts of liquidity ratios on profitability.

Interdisciplinary Journal of Research in Business, vol.1, issue.7, july, 2011, pp.95-98

SANTOS, A.F. e GREUEL, M.A. Análise da Gestão Financeira e Econômica dos Clubes Brasileiros de Futebol: Uma Aplicação da Análise das Componentes Principais. XIII Semead - Seminários em Administração. Fea/Usp: setembro, 2010. Disponível em: http://www.ead.fea.usp.br/semead/13semead/resultado/trabalhosPDF/261.pdf. Acesso em 13 de mar. de 2014.

SOUSA, R. L. S.; SANTOS, O. M. D. Nível de Evidenciação das Instituiçóes Financeiras à Luz das Exigências DOCPC 40 - Instrumentos Financeiros. Contexto - Revista do Programa de Pós-Graduação em Controladoria e Contabilidade da UFRGS, v. 17, n. 35, p. 105-122, 2017.

SURESH, A.S. A Study of Fundamental and Technical Analysis. International Journal of Marketing, Financial Services e Management Research, vol.2, n.5, may, 2013.

TAGLIARI, T. C.; SANTOS, D. F. L.; RODRIGUES, S. V. Há Benefícios na Diversificação das Fontes de Endividamento no Setor Imobiliário no Brasil?. Revista de Administração, Contabilidade e Economia da FUNDACE, v. 8, n. 2, p. 106-123, 2017. DOI: http://dx.doi.org/10.13059/racef.v8i2.444 
TEIXEIRA, S. C. Utilização de análise de componentes principais em séries temporais. Dissertação de mestrado apresentada ao Instituto de Matemática e Estatística da Universidade de São Paulo. São Paulo: Fevereiro, 2013.

THE ECONOMIST. Infrastructure in Brazil: Not many aboard. Print Edition. São Paulo: Finance and Economics, 16 de jul de 2015. Disponível em: https://www. economist.com/finance-and-economics/2015/07/16/not-many-aboard Acesso em $10 \mathrm{de}$ abril de 2019.

VALOR. Greve dos caminhoneiros: uma aula de economia brasileira. Valor Econômico, 30/05/2018. Disponível em: https://www.valor.com.br/financas/5558899/greve-doscaminhoneiros-uma-aula-de-economia-brasileira Acesso em 02 de abril de 2019.

WHITE, G.; SONDHI, A.C. e FRIED, D. The Analysis and Use of Financial Statements, 3rd Edition. Hardcover: December, 2002. 